\title{
Volt / VAR Regulation in Energy Transmission Systems Using SVC and STATCOM Devices
}

\author{
H.F. CARLAK and E. KAYAR
}

\begin{abstract}
To ensure energy continuity in the interconnected power systems, production and consumption amounts should be in balance, and that can be possible by providing constant voltage and frequency. Otherwise, undesirable large dynamic oscillations, voltage collapse may occur, and the quality of the electrical energy deteriorates. In this study, the power system of the Denizli Region in the Western Mediterranean Region is modeled using realistic national data. The simulation study is carried out to obtain the voltages, active and reactive powers of buses in the case of no-fault and fault occurrence. Using FACTS (Flexible Alternating Current Transmission Systems) technology such as SVC and STATCOM, the power systems can be controlled, and the carrying capacities can be improved within specified limits. Facts devices are capable of producing and consuming reactive power depending on immediate needs, safe and operating flexibility, and having a high reaction time in the simulation studies. The maximum load limits are increased, and the control of the power system is facilitated. STATCOM provides $31.09 \%$ more achievement with respect to $S V C$ device at energy production and consumption rates for the modeled pilot region. The reliability of the power system has been increased against a voltage collapse, thanks to the SVC and STATCOM controllers. Furthermore, the voltage stability of the generator is also raised, and correspondingly the capacity of the power system enhances. The results are compared to the existing system, and the obtained improvements may be assessed for the enhancement of the interconnected network grid of Turkey.
\end{abstract}

Index Terms-Power System Analysis, Statcom, Svc, Facts, Voltage Regulation, Reactive Power Regulation

\section{INTRODUCTION}

$\mathrm{P}$ OWER ELECTRONICS-BASED Flexible Alternating Current Transmission Systems (FACTS) are used for active power, reactive power, impedance, and voltage control in power systems.

HAMZA FEZA CARLAK, is with Department of Electrical and Electronics Engineering Akdeniz University, Antalya, Turkey, (e-mail: fezacarlak@akdeniz.edu.tr).

(iD) https://orcid.org/0000-0002-8561-4591

ERGIN KAYAR, is with Department of Electrical and Electronics Engineering Akdeniz University, Antalya, Turkey, (e-mail: erginkayar07@gmail.com).

https://orcid.org/0000-0002-7356-2165

Manuscript received July 23, 2019; accepted October 16, 2019.

DOI: $\underline{10.17694 / \text { bajece. } 595761}$
In the recent years, flexible AC transmission system (FACTS) technology has been used in efficient energy utilization, demand control, power quality enhancement, harmonic mitigation, voltage regulation, reactive power compensation, transient and steady state voltage stability enhancement, power loss reduction, power conditioning and quality improvement [1, 2, 3, 4]. The emerging use of renewable and distributed generation has accelerated and expanded the role of power electronic devices for efficient electrical utilization and enhanced security and reliability of the electric utility grid [5]. Also, new applications have emerged for standalone microgrids with regards to renewable energy utilization using solar photovoltaic (PV) systems, microhydroelectric systems, the wind, biomass, waste-to-energy and hybrid ac-dc sources with battery energy storage for remote villages [6]. Renewable energy sources (RESs) are utilized at an accelerating rate and connected to both transmission and distribution/utilization systems using power electronic converters. This results in increased harmonics and deterioration of power quality at the point of common coupling. Power quality issues and mitigation have emerged as serious challenges and issues facing electric utilities and industrial/commercial/residential users [7].

Various FACTS devices and control strategies can help to mitigate power quality problems. For efficient use of power system resources, the concept of FACTS has been introduced in the late 1980's. The basic concept of FACTS devices has been based upon the use of high-voltage power electronics to control real and reactive power flow and voltage in the transmission system [8]. Extensive research has focused on new topologies and architectures of voltage-source converters (VSCs) to increase the performance of FACTS devices in transmission and distribution systems and consequently enhance power system security $[9,10]$. FACTS devices and smart control strategies have been gaining a more prominent role in energy generation from renewable sources [11]. The results of the implementation of FACTS devices in smart grids with renewable systems are encouraging $[12,13]$.

Determining the location and size of FACTS devices which provide important benefits in power flow control, increasing transmission transfer capacity, voltage stability, reactive power control is of great importance both technically and economically. The voltage regulation is provided by the help of FACTS devices to prevent the system from operating under 
unstable conditions that may cause the partial or complete collapse. The study is implemented by modelling 10 bus prototype model of the energy transmission system of Denizli Region in the Western Mediterranean Region of the dynamic model SVC (Static Var Compensator), and STATCOM (Static Synchronous Compensators) devices using realistic data. The analyses are implemented to determine the voltage stability of the pilot electrical power system region. Optimum location and performance of FACTS devices in terms of bus voltage fluctuations and line capacities are tested. Simulation study is carried out using national data of the realistic pilot region and the results are compared to the current system and the benefits may be evaluated for the improvement of the Turkish interconnected system. The aim of the study is minimizing losses and providing voltage and reactive power control by using FACTS technology instead of the existed capacitor groups or reactors which have pretty long reaction times.

The usage and development of FACTS in power transmission systems brings many applications to improve the stability of power systems [14]. They may be used to increase the stability of the system and control the power flow. The most significant advantages of such devices are their flexibility and controllability [15]. Their applications are generally concentrated on issues such as increasing voltage stability, damping oscillations, voltage control in power systems and improving stability of power systems. These applications can be made by checking the voltage value and the phase angle [16].

Reactive compensation using STATCOM and DGMSTATCOM (Pulse Width Modulation Static Synchronous Compensator) devices were performed in Coteli's study to compare the controller performances of both devices. The simulation study shows that STATCOM responds very quickly to unexpected sudden voltage variations [17]. A methodology for introducing FACTS models into the energy transmission network using DIG-SILENT Power Factory program was disclosed in Cepeda et al's study [18]. The application methodology SVC, TCSC, SSSC, and STATCOM for the application of DIG-SILENT Power Factory to the stability studies of electrical power systems involves four stages. The SVC, TCSC (Thyristor Controlled Series Capacitor), SSSC (Static Synchronous Series Compensator), and STATCOM models are properly applied into the system and the contribution of FACTS devices in improving the stability of the power system were denoted.

In the literature, the studies on FACTS technology of power systems have been mostly carried out by classifying the FACTS controllers. However, feasibility studies have not been already carried out by using FACTS technology for the realistic power system model, which is constructed with realistic values by taking into account all parameters for the energy transmission system which is the novelty of this study.

\section{METHOD AND MODELING}

\section{A. Load Flow Analysis}

In the feasibility studies of the modelled region, the power system elements such as transformers, capacitors, reactors and FACTS devices used in electrical power systems, which play an active role in electrical networks, are analyzed by performing load flow algorithms.

The effects of generators, non-linear loads, and other devices connected to the grid nodes are reflected in the node current. Constant impedance loads (linear) are also included in the node admittance matrix. In the formation of node equations, the equation will be linear if I current inputs are known in nonlinear power flow equations. The current inputs depend on the $\mathrm{P}, \mathrm{Q}$ and $\mathrm{V}$ parameters in any $\mathrm{k}$ node:

$\left[\begin{array}{c}\Delta P_{2}^{(k)} \\ \vdots \\ \Delta P_{n}^{(k)} \\ --- \\ \Delta Q_{2}^{(k)} \\ \vdots \\ \Delta Q_{n}^{(k)}\end{array}\right]=\left[\begin{array}{cccccc}\left(\frac{\partial P_{2}}{\partial \delta_{2}}\right)^{(k)} & \cdots & \left(\frac{\partial P_{2}}{\partial \delta_{n}}\right)^{(k)} & \left(\frac{\partial P_{2}}{\partial \mid V_{2}}\right)^{(k)} & \cdots & \left(\frac{\partial P_{2}}{\partial||_{n}}\right)^{(k)} \\ \vdots & \ddots & \vdots & \vdots & \ddots & \vdots \\ \left(\frac{\partial P_{n}}{\partial \delta_{2}}\right)^{(k)} & \cdots & \left(\frac{\partial P_{n}}{\partial \delta_{n}}\right)^{(k)} & \left(\frac{\partial P_{n}}{\partial \mid V_{2}}\right)^{(k)} & \cdots & \left(\frac{\partial P_{n}}{\partial \mid V_{n}}\right)^{(k)} \\ \left(\frac{\partial Q_{2}}{\partial \delta_{2}}\right)^{(k)} & \cdots & \left(\frac{\partial Q_{2}}{\partial \delta_{n}}\right)^{(k)} & \left(\frac{\partial Q_{2}}{\partial||_{2}}\right)^{(k)} & \cdots & \left(\frac{\partial Q_{2}}{\partial|V|_{n}}\right)^{(k)} \\ \vdots & \ddots & \vdots & \vdots & \ddots & \vdots \\ \left(\frac{\partial Q_{n}}{\partial \delta_{2}}\right)^{(k)} & \cdots & \left(\frac{\partial Q_{n}}{\partial \delta_{n}}\right)^{(k)} & \left(\frac{\partial Q_{n}}{\partial \mid V_{2}}\right)^{(k)} & \cdots & \left(\frac{\partial Q_{n}}{\partial|V|_{n}}\right)^{(k)}\end{array}\right]\left[\begin{array}{c}\Delta \delta_{2}^{(k)} \\ \vdots \\ \Delta \delta_{n}^{(k)} \\ ---- \\ \Delta|V|_{2}^{(k)} \\ \vdots \\ \Delta|V|_{n}^{(k)}\end{array}\right]$

Where, $\mathrm{P}$ and $\mathrm{Q}$ are specified for load bus bars and $\mathrm{P}$ and $\mathrm{V}^{\sim}$ are defined for voltage-controlled bus bars. For other node types, the relations between $\mathrm{P}, \mathrm{Q}, \mathrm{V}^{\sim}$ and $\mathrm{I}^{`}$ are defined by the characteristics of the devices connected to those nodes. The boundary condition problems brought about by various types of nodes is turned into a nonlinear problem and solved iteratively using Fast-Decoupled Newton-Raphson Method which is an accelerated version of the Newton-Raphson Method [19].

In order to further reduce the calculation time of the FastDecoupled Method, the Jacobian matrix is created according to the initial conditions and the Fast-Decoupled method with constant Jacobian is going to be applied during the calculation.

$$
\begin{gathered}
\frac{\partial P_{i}}{\partial V_{j}}=2 V_{i} G_{i i}+\sum_{\substack{k=1 \\
\neq i}}^{n} V_{k} Y_{i k} \cos \left(\theta_{i}-\theta_{k}-\alpha_{i k}\right) \\
=2 V_{i} G_{i i}+\sum_{\substack{\begin{subarray}{c}{k=1 \\
\neq i} }} \\
{n}\end{subarray}}^{n} V_{i k}\left[\cos \left(\theta_{i}-\theta_{k}\right) \cos \alpha_{i k}+\sin \left(\theta_{i}-\right.\right. \\
\left.\left.\theta_{k}\right) \sin \alpha_{i k}\right] \\
=2 V_{i} G_{i i}+\sum_{\substack{k=1 \\
\neq i}}^{n} V_{k}\left[G_{i k} \cos \left(\theta_{i}-\theta_{k}\right)+B_{i k} \sin \left(\theta_{i}-\right.\right. \\
\left.\left.\theta_{k}\right)\right] ; j=i
\end{gathered}
$$

$$
\begin{aligned}
& \frac{\partial P_{i}}{\partial V_{j}}=V_{i} Y_{i j} \cos \left(\theta_{i}-\theta_{j}-\alpha_{i j}\right) \\
\quad & =V_{i} Y_{i j}\left[\cos \left(\theta_{i}-\theta_{j}\right) \cos \alpha_{i j}+\sin \left(\theta_{i}-\theta_{j}\right) \sin \alpha_{i j}\right] \\
= & V_{i}\left[G_{i j} \cos \left(\theta_{i}-\theta_{j}\right)+B_{i j} \sin \left(\theta_{i}-\theta_{j}\right)\right] ; \quad j \neq i
\end{aligned}
$$

$$
\frac{\partial P_{i}}{\partial V_{i}} \approx 0 \quad \text { ve } \quad \frac{\partial P_{i}}{\partial V_{j}} \approx 0 \Rightarrow J_{2} \approx 0
$$




$$
\begin{aligned}
& \frac{\partial Q_{i}}{\partial \theta_{j}}=\sum_{\substack{k=1 \\
\neq i}}^{n} V_{i} V_{k}\left[G_{i k} \cos \left(\theta_{i}-\theta_{k}\right)+B_{i k} \sin \left(\theta_{i}-\theta_{k}\right)\right]: j=i(7) \\
& \frac{\partial Q_{i}}{\partial \theta_{j}}=-V_{i} V_{j}\left[G_{i j} \cos \left(\theta_{i}-\theta_{j}\right)+B_{i j} \sin \left(\theta_{i}-\theta_{j}\right)\right] ; j \neq i \\
& \frac{\partial Q_{i}}{\partial \theta_{i}} \approx 0 \quad \text { ve } \frac{\partial Q_{i}}{\partial \theta_{j}} \approx 0 \Rightarrow J_{3} \approx 0 \\
& {\left[\begin{array}{l}
\Delta P \\
\Delta Q
\end{array}\right]=\left[\begin{array}{cc}
J_{1} & 0 \\
0 & J_{4}
\end{array}\right]\left[\begin{array}{l}
\Delta \theta \\
\Delta V
\end{array}\right]}
\end{aligned}
$$

In this study, dynamic load flow analysis is performed under discontinuously distributed generation, and variable power demand situations and hourly changes of electrical parameters of busbars are calculated. Thus, the effects of distributed generation, which is formed from sources showing production discontinuity, on the voltage and power factor stability of busbars can be analyzed in the face of changing power demands.

\section{B. Theoretical Background}

Compensation is made by the help of static controllers and power electronics elements to improve the controllability of the power transferred by the power transmission lines and to provide the reactive power demand of the system quickly. Shunt reactive compensator devices can be designed with switching type converters. FACTS devices can produce and consume reactive power utilizing switched converter circuits without the need for capacitor or reactor groups in the compensation of transmission lines. Sine FACTS devices, which constitute modern compensation methods, react in a short time, the controllability of each phase separately, can compensate unbalanced loads, the use of these devices is an essential [20]. These devices increase the stability limits of the transmission lines when used properly. Today, many power flow controllers have been developed under the name FACTS. The most commonly used ones are; Static Var Compensator (SVC), Thyristor Controlled Series Capacitor (TCSC), Static Compensator (STATCOM), Combined Power Flow Controller (UPFC), Phase Shifter and Static Synchronous Serial Capacitor (SSSC).

The SVC is part of a family of FACTS devices that can be connected in parallel to the power system to generate or consume reactive power to control power system parameters, such as voltage. Its primary purpose is to produce and consume fast effective, precise and adjustable continuous reactive power to the system, have a high response time, operate in an unlimited range, are safe and have operational flexibility [21]. $\mathrm{SVC}$ is also used for dynamic power factor correction when the demand for reactive power in large industrial plants is high, SVC increases the power factor of the plant, minimizes voltage fluctuations at the input of the plant and reduces the operating costs of the plant. It's mainly used in SVC power systems for the voltage control and system stability improvement.

The operating principle of the SVC element is based on obtaining shunt impedance of variable value by inserting and removing the capacitors and reactors into the network depending on the calculated trigger angles. Reactive power can be adjusted in a wide range from maximum capacitive reactive power value to maximum inductive reactive power value in the busbar to which static VAR generator is connected with an appropriate triggering [22]. The inductance determines the capacitive or inductive operation of the device. The value of inductance is determined by the following equation [23].

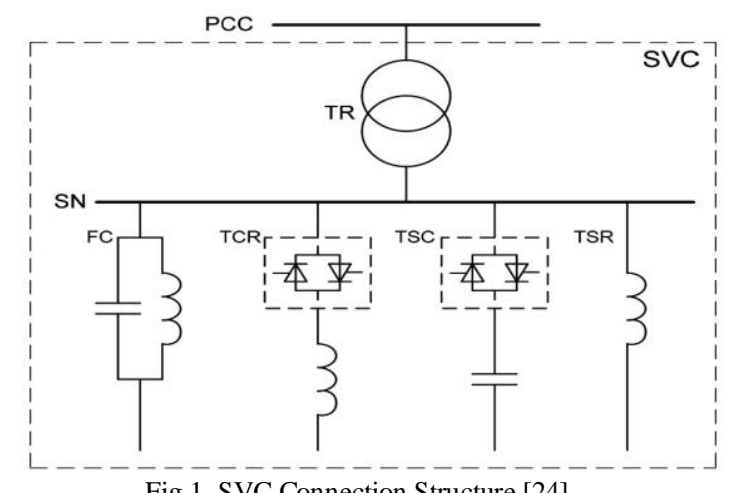

Fig.1. SVC Connection Structure [24]

STATCOM, known as Advanced Static Var Compensator (ASVC), is a FACTS controller, which is controlled to draw reactive current from the power system and connected to an inverter between a dc energy storage element and a three-phase system. A shunt is connected to the STATCOM transmission line, regulating the voltage of the transmission line at the connection point by drawing a controlled reactive current from the STATCOM transmission line [25]. A STATCOM controller consists of a connection transformer, voltage source inverter, and DC energy storage element (Fig.2.). Since the energy storage element is a tiny capacitor, it can only exchange reactive power.

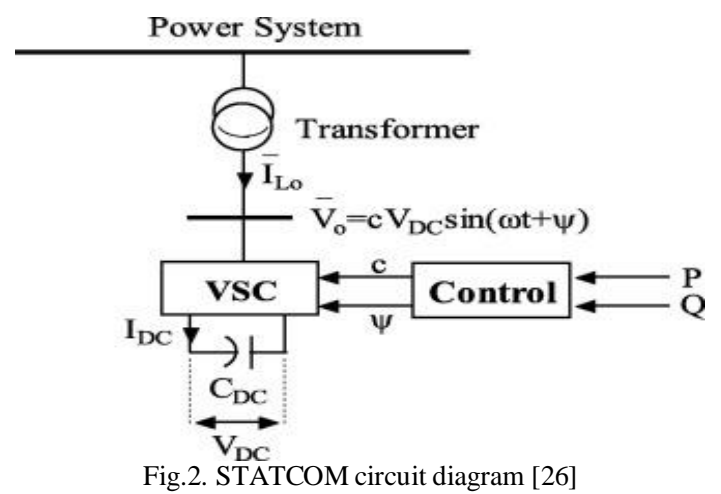

The controller used in the simulation is the AC voltage control mode. The power is divided into two main parts. One is for an angle order, and another is for the rule of modulation index. The angle is ordered in such a way that the net real power absorbed from the line by this shunt FACTS device is equal to the losses of the converters and the transformer only. The remaining capacity of this shunt converter can be used to exchange reactive power with the line so to provide VAR compensation at the connection point. The reactive power is electronically provided by the shunt converter and the active power is transmitted to the DC terminals. The shunt converter reactive current is automatically regulated to maintain the transmission line voltage at the point of connection to a reference value. The line voltage and DC link voltage across 
capacitor are measured to calculate the amount of reactive power to regulate the line voltage, and consequently, the modulation index is varied in such a way as to calculate reactive power can be injected at the point of connection, and thus the shunt FACTS device acts as a voltage regulator [27].

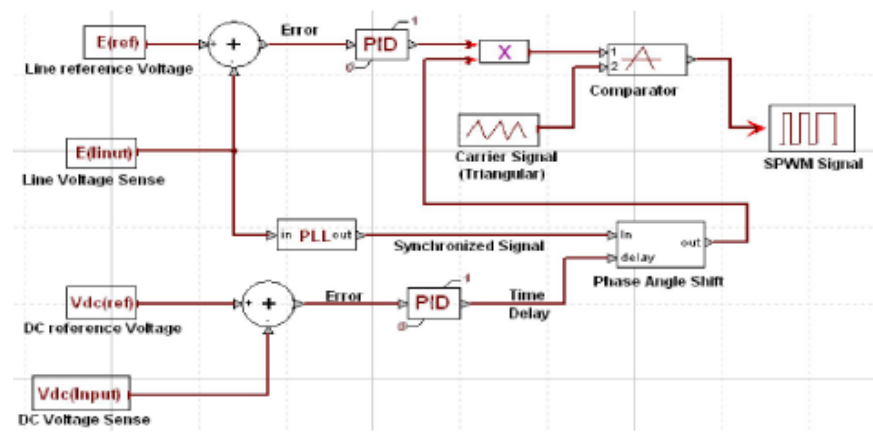

Fig. 2a. Block diagram of STATCOM Controller [27]

Varying the amplitude of the 3-phase output voltage of the voltage-driven inverter, STATCOM can be controlled whether to generate or draw reactive power. If the output voltage $\left(\mathrm{V}_{0}\right)$ of the inverter is greater than the ac system voltage $\left(\mathrm{V}_{\mathrm{ac}}\right)$, then the ac current $\left(\mathrm{I}_{\mathrm{ac}}\right)$ flows from the inverter to the ac system and generating reactive power via the transformer reactance. In this case, the inverter generates capacitive current for the ac system at an angle beyond its voltage. If the amplitude of the inverter output voltage is smaller than the ac system voltage, the ac current flows from the ac system to the voltage source inverter. And hence, the inverter draws an inductive current at an angle behind the voltage and consumes an inductive reactive power. If the output voltage of the inverter and the amplitude of the ac system voltages are equal, there will be no ac current flow from the inverter to the ac system. In short, the inverter will not produce or consume reactive power [28].
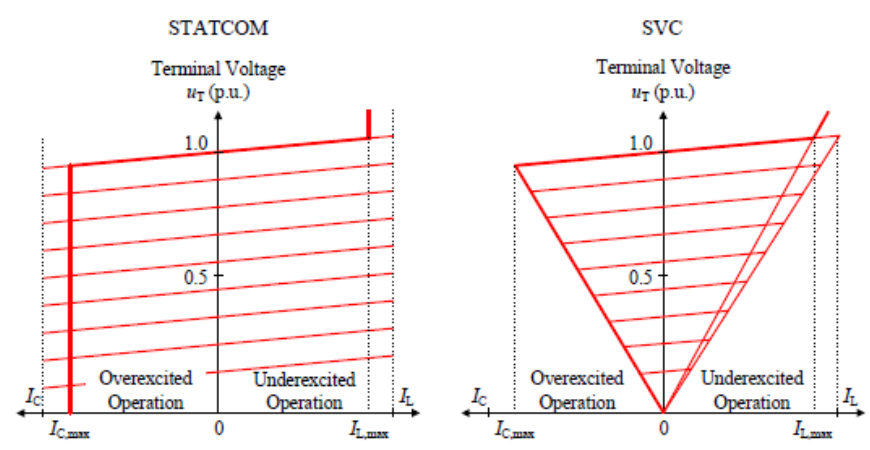

Fig.3. STATCOM, SVC, V-I characteristics [29]

Fig. 3. shows the SVC and STATCOM V-I characteristics. At low voltages, STATCOM current supply capacity is much better than SVC. STATCOM can provide either full capacitive or full inductive output current at any system voltage. The amount of reactive power compensation provided by STATCOM is higher than the amount of reactive power provided by SVC. Since at a low voltage level in the SVC, reactive power decreases proportionally with the square of the voltage, while STATCOM decreases linearly with the voltage.
This makes STATCOM's reactive power more controllable than the SVC [30].

\section{SIMULATION STUDIES}

\section{A. Modeling}

The realistic field data of the West Mediterranean Denizli energy transmission model is used to model the pilot power system region. The energy transmission model was created using the Dig-SILENT Power Factory program (Fig. 14). FACTS devices are connected to transformer substations and load flow analysis and voltage fluctuation controls are implemented. SVC and STATCOM which are FACTS controllers were connected to the power grid and analyses were carried out for various situations such as voltage drop and instantaneous power generation. The effects of the results on increasing the reliability and stability of the system and limiting the effects of faults and hardware defects were investigated. Moreover, increasing the stability of the voltage and power control of the Turkish interconnected system leads to more continuous, efficient, quality and economical way of providing electrical energy. Since the SVC and STATCOM devices are connected in parallel to the electrical power system, no auxiliary virtual bus is needed. In the modelling, lower and upper voltage limit values are defined as (0.9-1 pu) and (1-1.1 $\mathrm{pu})$ for the $160 \mathrm{kV}(1 \mathrm{pu})$ base voltage value. Capacitor banks, SVC and STATCOM devices are modelled separately in Denizli-1' bus bar. The simulation study was carried out with balanced 3-phase system voltages during 4-second steps over a total of 20-second operation duration in the case of one of the transmission lines (Denizli-2, Denizli-4 line-2a) of the Western Mediterranean region is out of order. The loading range of line and busloads of the energy transmission system varies between $15 \%$ and $20 \%$, voltage is $1 \mathrm{pu}$, and the system production is $9,12 \%$ for $\mathrm{G} 1$ (Generator 1 ), $68,41 \%$ for $\mathrm{G} 2$ (Generator 2 ), and $74,39 \%$ for G3 (Generator 3). Voltage simulation values of Denizli-1, Denizli-4, and Acarsoy. In case of steady state or transient failures, the voltage fluctuations of the energy transmission system network of Denizli-1, Denizli-4, Acarsoy, and Mains bus bars have been analyzed.

\section{B. Simulation Results}

The effects of Capacitor Banks, STATCOM and SVC on the stability limits of the system against voltage collapses and also the elimination of voltage oscillations after the disturbing effects such as faults have been evaluated. The optimum reactive power value supported from capacitor banks are obtained as 17.2 MVAr. Therefore, capacitor banks are adjusted to inject $18 \mathrm{MVAr}$ to the power network. The line voltage stabilities improve by the help of FACTS devices (Fig.4.). STATCOM provides more stability and also faster reaction time compared to SVC device (Fig.5.).

The voltage-loading curves for the most critical bus bars with voltage regulation problems have been evaluated in the modelled Western Mediterranean electricity transmission system. When SVC and STATCOM systems are inserted to the power system, their contribution to the reactive power has been examined and to what extent the system increases the loading limits in case of failure of the lines supplying Denizli-1 bus bar has been investigated (Fig. 6.). The load flow study has been 
implemented at the fault case and Denizli-1 bus bar is obtained as the most critical bus bar. The voltage stability fluctuation has been shown when SVC or STATCOM is added to Denizli-1 bus bar in case of different disturbing effects in the system.

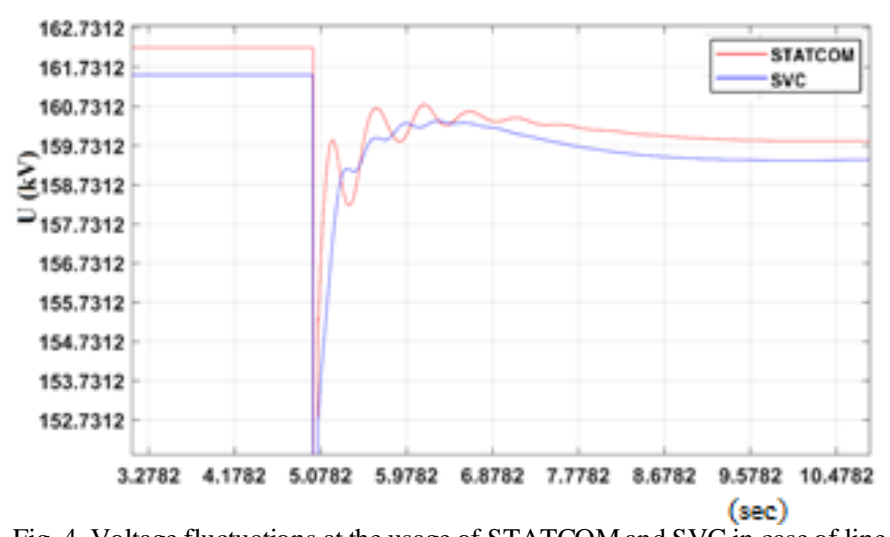

Fig. 4. Voltage fluctuations at the usage of STATCOM and SVC in case of line faults.

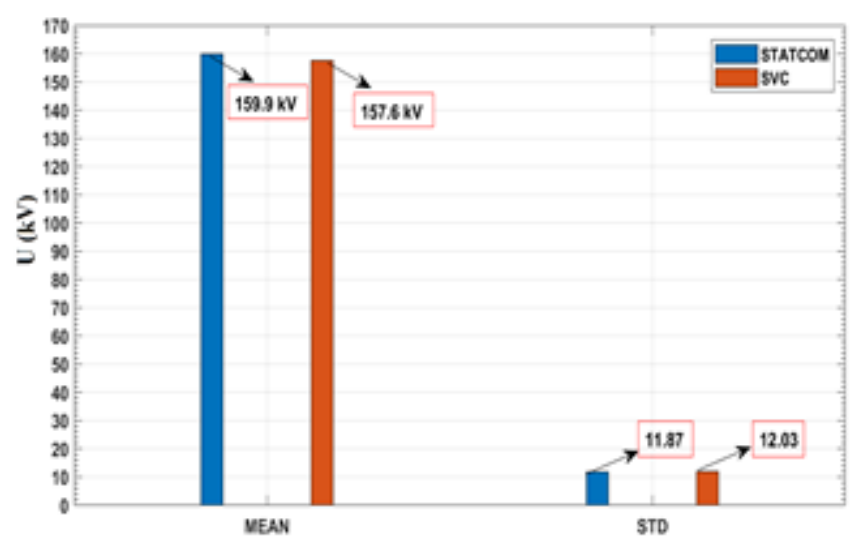

Fig.5. Mean and standard deviation values of bus voltages at the usage of STATCOM and SVC in case of faults

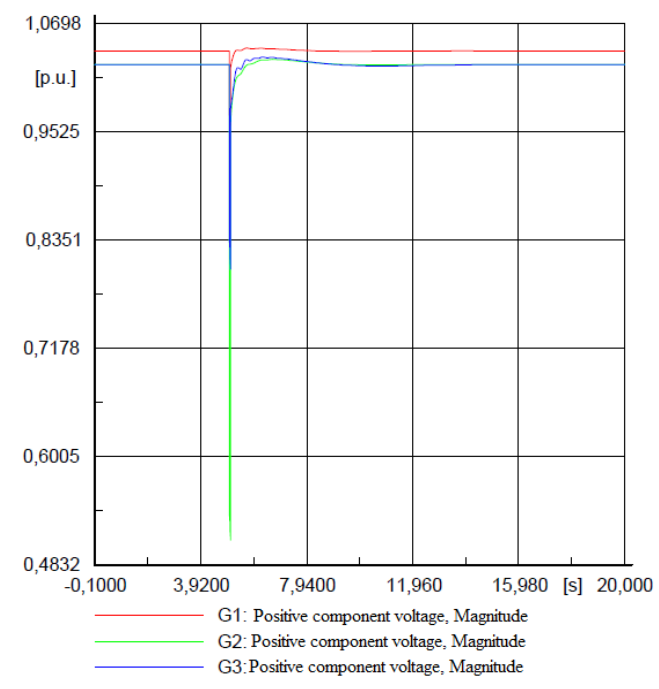

(STATCOM)

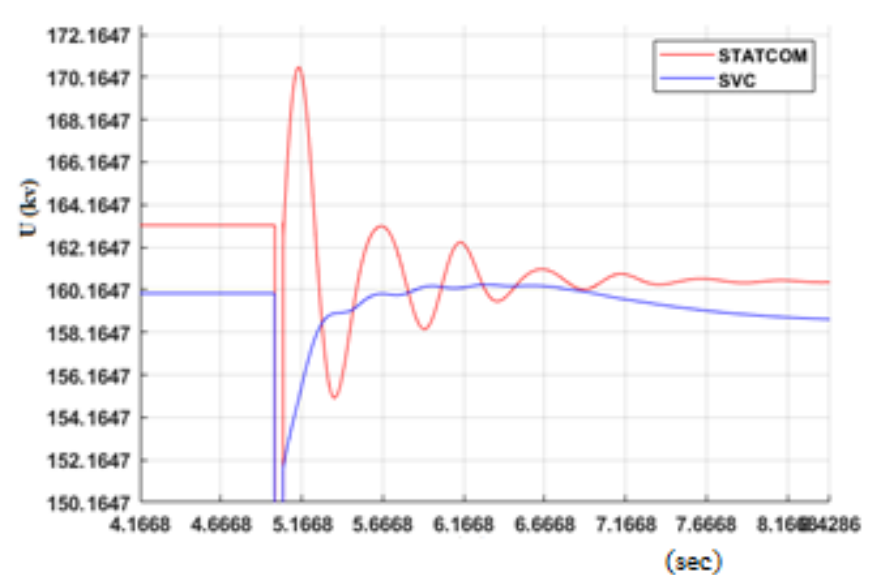

Fig. 6. Loading limits of the critical bus voltages at the usage of STATCOM and SVC in case of faults

As a result of load flow analysis, SVC and STATCOM were added in parallel to the required bars, and by providing voltage regulation, the points where the system suffered voltage collapse were identified and the effectiveness of FACTS devices at this point was evaluated. The SVC and STATCOM controllers have been significantly increased the reliability of the system against voltage collapses. STATCOM shows better performance and operates more stable in reactive power loading situations, and also provides the best power transfer in terms of active and reactive power values according to the simulation results. Required reactive power compensation is rapidly achieved with STATCOM, and despite sudden load changes and different load characters, it provides the desired reference voltage value of the bus bar.

When the rotor angle and rotor speed oscillations of the generators are examined, it is seen that their contribution to the oscillation suppression improves the generator voltage stability and helps to increase the reliability and capacity of the power system (Fig. 7. \& Fig. 8a, 8b). With the use of STATCOM, inductive and capacitive energy is given to the pilot power system, making the system work much more stable.

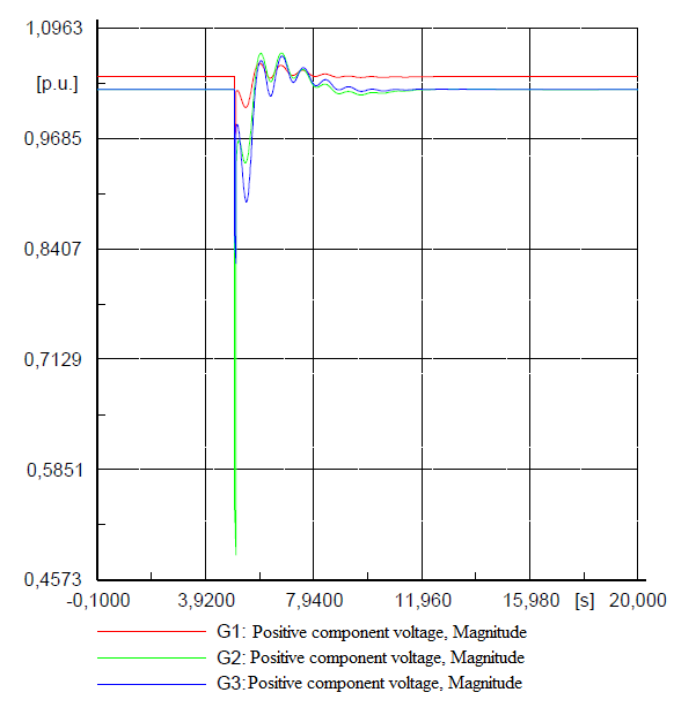

(SVC) 
Fig.7. Generator voltages at the usage of STATCOM and SVC
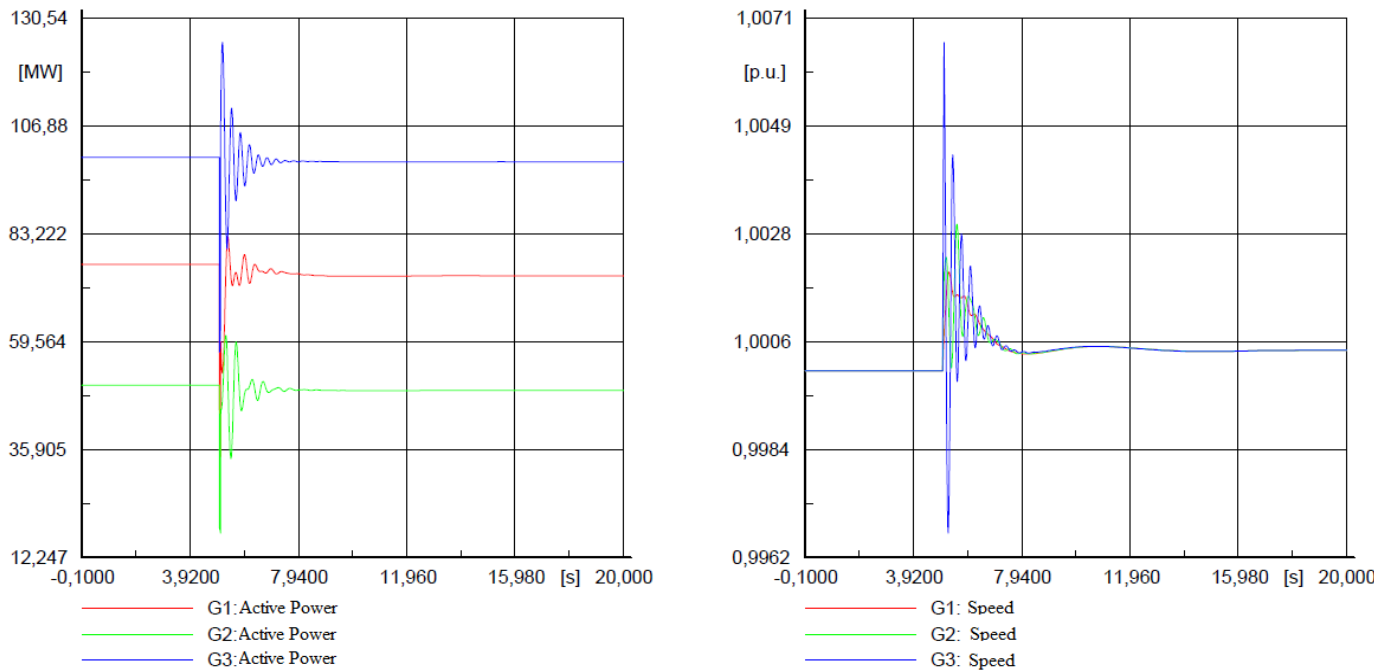

(a) STATCOM

Fig. 8.a. Rotor angle and rotor speed oscillations of generators at the usage of STATCOM
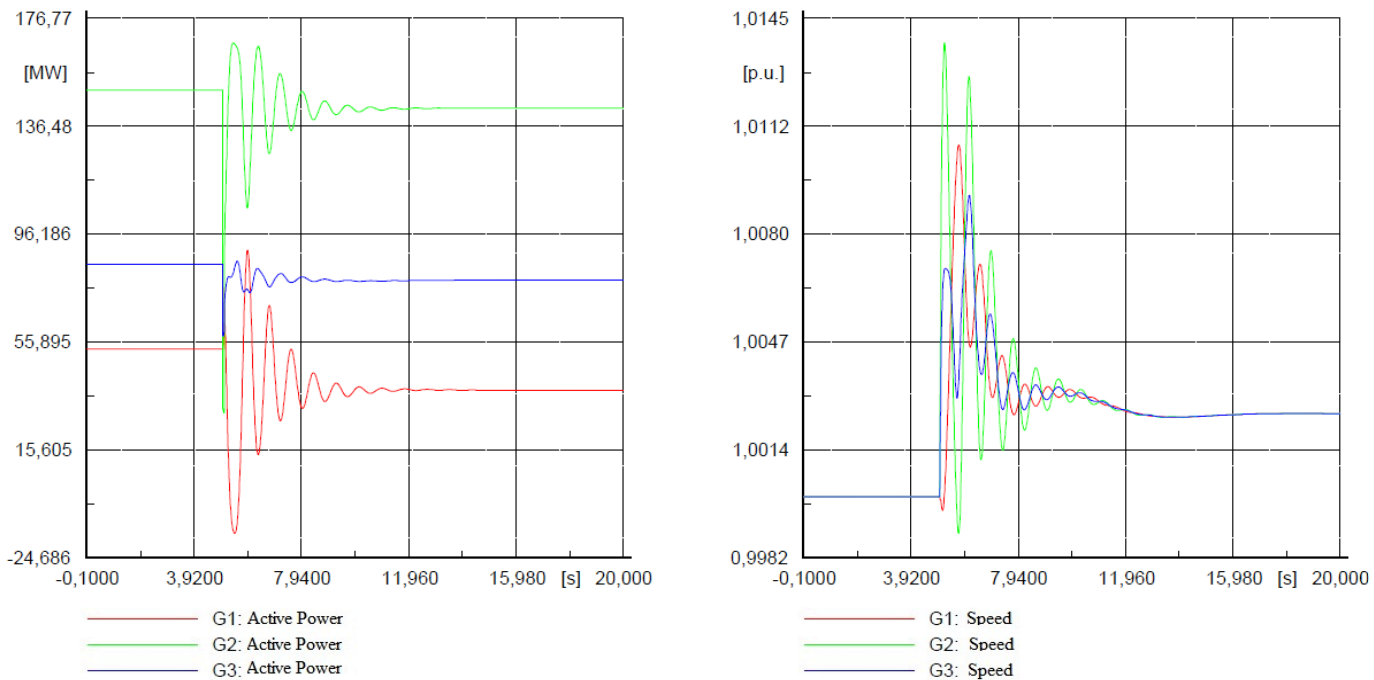

(b) SVC

Fig. 8.b. Rotor angle and rotor speed oscillations of generators at the usage of SVC

\section{Factors Causing Technical Losses in Electrical Grids}

The characteristics of a power system change with time as the load grows and production increases. If the transmission facilities are not sufficiently developed, the power system becomes weaker against the steady state, and transient state problems and the stability limits are narrowed [31]. Transmission system limitations may include one or more characteristics such as steady state power transfer limit, voltage stability limit, dynamic voltage limit, transient stability limit, power system surge damping limit, loop flow limit, thermal limit, and short circuit current limit. Each transmission barrier or regional restriction has one or more level problem stages [30]. In each application, a FACTS controller is used to alleviate certain transmission limitations, to facilitate distribution of production, and to provide adequate system reliability [32]. Losses in electrical systems can be analyzed in three main categories as production, transmission, and distribution losses. The majority of electrical losses occur in transmission and distribution systems. Approximately $6 \%$ of the generated electricity is due to internal loss and internal consumptions [33]. Therefore, the reduce of electrical losses is of great importance for the efficiency of electrical energy systems. Reasons for technical losses in electrical systems can be categorized as harmonic distortion, improper grounding of consumer loads, overloaded and long phase lines, voltage drops and use of non-standard equipment, reactive power drawn from the electrical grid [34]. Fig. 9 and 10 denote that STATCOM technology automatically activates and deactivates this process much faster and more stable than SVC devices, and hence minimizing losses and increasing the operating limits of the modelled transmission system. STATCOM, which has a flexible working structure, is more effective than SVC in reducing losses. 
The effects of active and reactive power flow and the critical power system parameters such as total transmission losses on the transmission line are investigated when FACTS devices are inserted. In the usage of SVC and STATCOM, the differences of consumed and generated average active power were 0.9361 and $0.645 \mathrm{MW} / \mathrm{h}$ respectively (Fig.9. \& 10.). STATCOM provides $31.09 \%$ more achievement with respect to SVC device, and this corresponds to $0.2911 \mathrm{MW} / \mathrm{h}$ less generation and consumption loss.

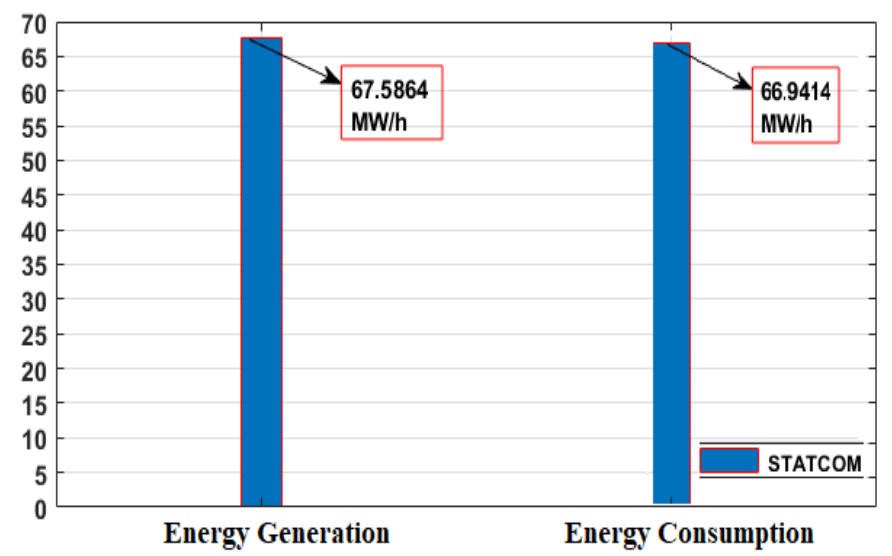

Fig.9. Energy production and consumptions at the usage of STATCOM

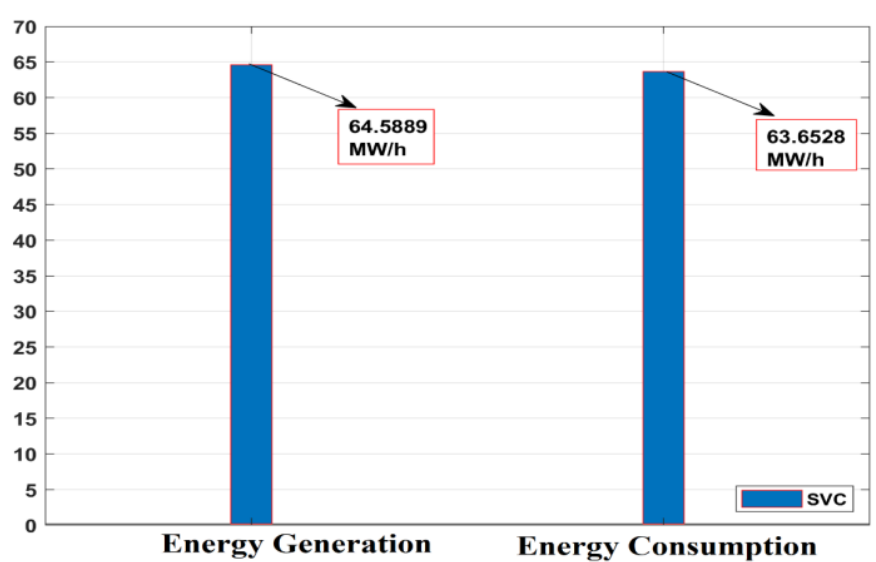

Fig.10. Energy production and consumptions at the usage of SVC

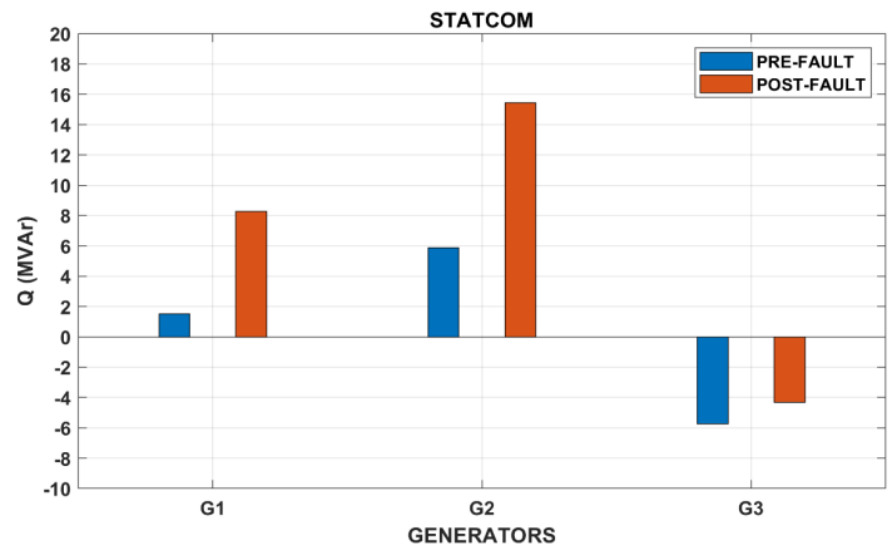

Fig.11. Generator Reactive Power Generations (STATCOM) Before/After Line Faults

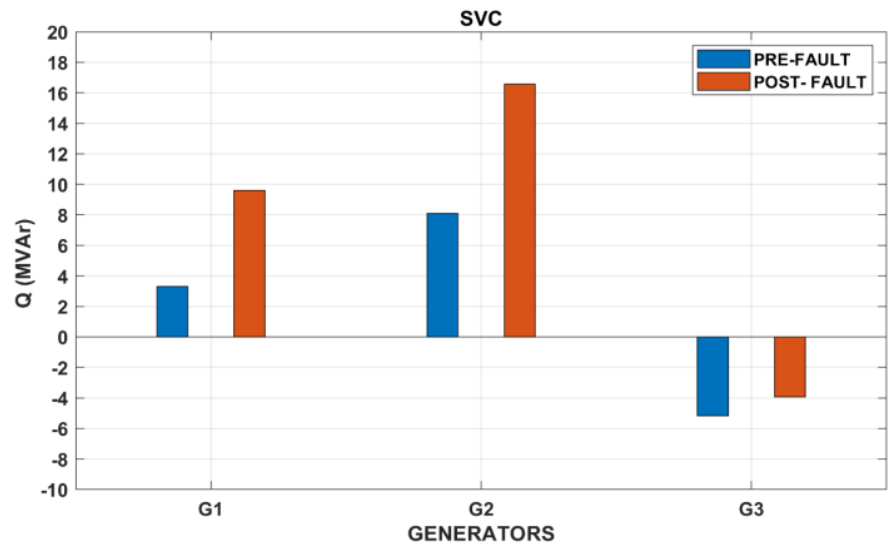

Fig.12. Generator Reactive Power Generation (SVC) Before/After Line Faults

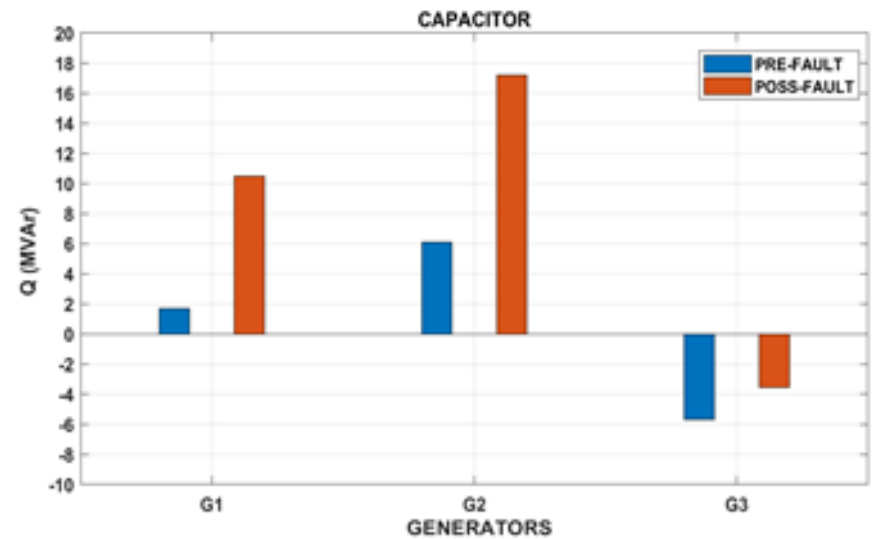

Fig.13. Generator Reactive Power Generation (Capacitor) Before/After Line Faults

In the simulation study, line faults resulted in critical increases in generator loadings. Reactive power loadings may be reduced by the usage of capacitor banks, SVC, and STATCOM. The total reactive power generation of three generators after the faults are 24.139, 22.249, and 19.389 MVAr for capacitor banks, SVC and STATCOM, respectively. The results depict that the lowest reactive power necessity of the power network before/after the line faults occurs when STATCOM device is used (Fig. 11., 12. \& 13.).

The comparison of reactive compensation devices such as capacitor banks, SVC and STATCOM on active and reactive power loadings and reactive power losses are shown by Table I. Active power loadings, capacitive reactive loadings, and reactive power losses of the transmission lines have been reduced by SVC/STATCOM devices $0.24 \%, 0.55 \%, 1 \%$ respectively. SVC and STATCOM devices decrease the loadings and also reactive power losses more than capacitor banks. Considering the all Turkish electrical power system, these reductions in losses are going to constitute a very substantial economic benefit. Voltage stability of the grid was provided as a result of STATCOM and SVC use of the power system model of the Western Mediterranean region electricity power transmission system of the Denizli region. Fluctuations of voltage stability in case of system overload or failure have been analyzed. Voltage and power stability values of the lines, and voltage values of load bus bars have been obtained for the generated power system model. Bus bar voltages are shown by 
using Capacitor, SVC, and STATCOM devices before and after faults (Tables II and III). As can be seen from the results, the STATCOM device regulates the voltage much better than SVC and capacitor banks. Bus bar voltages are hardly affected by the fault thanks to the use of STATCOM (Table III).

TABLE I

TRANSMISSION LINE STATUS (AT THE USAGE OF FACTS DEVICES) AFTER LINE FAULTS

\begin{tabular}{|l|l|l|l|l|l|l|}
\hline \multirow{2}{*}{ Lines } & \multicolumn{2}{|c|}{ ACTIVE POWER LOADING (\%) } & \multicolumn{2}{c|}{$\begin{array}{c}\text { CAPACITIVE REACTIVE } \\
\text { LOADING (MVAr) }\end{array}$} & \multicolumn{2}{c|}{$\begin{array}{c}\text { REACTVE POWER LOSS } \\
\text { (MVAr) }\end{array}$} \\
\cline { 2 - 7 } & $\begin{array}{l}\text { CAPACITOR } \\
\text { ENABLED }\end{array}$ & $\begin{array}{l}\text { SVC / STATCOM } \\
\text { ENABLED }\end{array}$ & $\begin{array}{l}\text { CAPACITOR } \\
\text { ENABLED }\end{array}$ & $\begin{array}{l}\text { SVNABLED } \\
\text { ENAM }\end{array}$ & $\begin{array}{l}\text { CAPACITOR } \\
\text { ENABLED }\end{array}$ & $\begin{array}{l}\text { SVC / STATCOM } \\
\text { ENABLD }\end{array}$ \\
\hline Line & 7.99699 & 7.99706 & 11.01927 & 10.99988 & -10.17619 & -10.15604 \\
\hline Line (1) & 1.91172 & 1.91000 & 11.10064 & 11.08061 & -11.10064 & -11.08061 \\
\hline Line (2) & 15.43685 & 15.4004 & 7.91846 & 7.87871 & -4.49485 & -4.45075 \\
\hline Line 1 & 30.22983 & 30.36543 & 8.97983 & 8.93827 & 3.32629 & 3.45375 \\
\hline Line 2a & 9.30884 & 9.22839 & 1.54765 & 1.54355 & -1.33054 & -1.32984 \\
\hline Line 2b & 9.13218 & 9.06786 & 13.81726 & 13.74428 & -12.07093 & -11.99212 \\
\hline Line 3 & 11.42976 & 11.36274 & 7.30717 & 7.29224 & -6.06996 & -6.06952 \\
\hline Line 4 & 25.05796 & 25.10335 & 10.30962 & 10.29939 & -0.41096 & -0.37028 \\
\hline Line 5 & 12.48466 & 12.4395 & 18.51381 & 18.49452 & -15.12844 & -15.12671 \\
\hline Line 6 & 19.07388 & 18.85184 & 15.77896 & 15.44046 & -5.70820 & -5.39699 \\
\hline
\end{tabular}

TABLE II

BUS VOLTAGES WHEN FACTS DEVICES OPERATES (THERE IS NO FAULT)

\begin{tabular}{|l|l|l|l|}
\hline Bus ID & $\begin{array}{c}\text { CAPACITOR } \\
\text { ENABLED }\end{array}$ & $\begin{array}{c}\text { SVC } \\
\text { ENABLED }\end{array}$ & $\begin{array}{l}\text { STATCOM } \\
\text { ENABLED }\end{array}$ \\
\hline DENIZLI-1 (kV) & 161.9342 & 160.0 & 160.0 \\
(pu) & 1.01208 & 1.0 & 1.0 \\
\hline DENIZLI-2 (kV) & 163.2398 & 163.1085 & 163.1085 \\
(pu) & 1.02024 & 1.01942 & 1.01942 \\
\hline DENİZLI-3 (kV) & 158.4197 & 158.3302 & 158.3302 \\
(pu) & 0.99012 & 0.98956 & 0.98956 \\
\hline DENIZLi-4 (kV) & 161.4339 & 161.0137 & 161.0137 \\
(pu) & 1.008961 & 1.00633 & 1.00633 \\
\hline ACARSOY (kV) & 165.177 & 165.08 & 165.08 \\
(pu) & 1.03235 & 1.03175 & 1.03175 \\
\hline NETWORK (kV) & 160.8582 & 160.7506 & 160.7506 \\
(pu) & 1.005361 & 1.00469 & 1.00469 \\
\hline
\end{tabular}

TABLE III

BUS VOLTAGES WHEN FACTS DEVICES OPERATES (AFTER LINE FAULT OCCURS)

\begin{tabular}{|l|l|l|l|}
\hline Bus ID & $\begin{array}{c}\text { CAPACITOR } \\
\text { ENABLED }\end{array}$ & $\begin{array}{c}\text { SVC } \\
\text { ENABLED }\end{array}$ & $\begin{array}{l}\text { STATCOM } \\
\text { ENABLED }\end{array}$ \\
\hline DENİZLI-1 (kV) & 157.8052 & 160.0 & 160.0 \\
(pu) & 0.98628 & 1.0 & 1.0 \\
\hline DENIZLI-2 (kV) & 162.1797 & 162.3029 & 162.3029 \\
(pu) & 1.01362 & 1.01439 & 1.01439 \\
\hline DENIZZLi-3 (kV) & 157.8219 & 157.9073 & 157.9073 \\
(pu) & 0.98638 & 0.98692 & 0.98692 \\
\hline DENİZLI-4 (kV) & 158.2907 & 158.8408 & 158.8408 \\
(pu) & 0.98931 & 0.99275 & 0.99275 \\
\hline ACARSOY (kV) & 164.3486 & 164.4754 & 164.4754 \\
(pu) & 1.02717 & 1.02797 & 1.02797 \\
\hline NETWORK (kV) & 159.9385 & 160.0793 & 160.0793 \\
(pu) & 0.99961 & 1.00049 & 1.00049 \\
\hline
\end{tabular}

\section{CONCLUSION}

Implementing voltage and reactive power control by SVC/STATCOM controller in the power system, technical losses can be reduced, and electrical energy can be transmitted in a stable, controlled, and most economical way. Results denote that the sensitivity of voltage and reactive power control are improved and the production and consumption balance become more stable by the usage of FACTS devices. When the modeled pilot region is evaluated in terms of oscillatory operation and voltage drop, FACTS devices can increase the maximum load point of the system against voltage collapse more than the continually operated capacitor banks. In case of failure of one of the lines in the network, it has been determined that FACTS devices can suppress oscillatory operation mode, which occurs at bus voltage, generator rotor speeds, and rotor angles. Results show that STATCOM and SVC systems increase the maximum load and limits, improve the stability limits in the case of a disturbing effect on the power system, and prevent the voltage collapse under overload conditions. The reactive power losses and correspondingly the electricity costs may be reduced by 1 $\%$ by SVC/STATCOM devices. STATCOM controllers have $\% 31.09$ higher performance compared to $S \mathrm{VC}$ at ass uring the energy production and consumption balance.

\section{ACKNOWLEDGMENT}

This study has been supported by Akdeniz University Scientific Research Projects Coordination Department within the scope of the project no: FBA-2018-3792 for the possibility to complete a scientific research.

\section{REFERENCES}

[1] Kalair A, Abas N, Kalair AR, Saleem Z, Khan N. "Review of harmonic analysis, modeling and mitigation techniques. Renew Sustain Energy" Rev 2017, 78 (10), pp. 1152-1187.

[2] Martínez EB, Camacho CÁ. "Technical comparison of FACTS controllers in parallel connection" J Appl Res Technol 2017, 15(1), pp.36-44.

[3] Jumaat SA, Musirin I, Baharun MM. "A voltage improvement of transmission system using static var compensator via matlab/Simulink" Indones J Electr Eng Comput Sci 2017, 6(2), pp. 1-17.

[4] Fadaee M, Radzi MAM. "Multi-objective optimization of a stand-alone hybrid renewable energy system by using evolutionary algorithms: a review. Renew Sustain Energy” Rev 2012, 16(5), pp. 3364-2269.

[5] Sadaiappan S, Renuga P, Kavitha D. "Modeling and simulation of series compensator to mitigate power quality problems" Int J Eng Sci Technol 2010, 2(12), pp. 7385-7394. 
[6] Liu L, Li H, Xue Y, Liu W. "Reactive power compensation and optimization strategy for grid-interactive cascaded photovoltaic systems" IEEE Trans Power Electron 2015, 30(1), pp. 188-202.

[7] Darabian M, Jalilvand A. "A power control strategy to improve power system stability in the presence of wind farms using FACTS devices and predictive control" Int J Electr Power Energy Syst 2017, 85(2), pp. 50-66.

[8] Sharaf AM, Gandoman FH. "A switched hybrid filter - DVS/green plug for smart grid nonlinear loads, in Smart Energy Grid Engineering" (SEGE), IEEE International Conference on; 17-19 Aug. 2015, pp. 1-6.

[9] Sharaf AM, Khaki B. Novel "switched capacitor-filter compensator for smart gridelectric vehicle charging scheme" in Proc. IEEE SGE, Oshawa, Canada; Aug 2012, pp.1-6.

[10] Abdelsalam AA, Desouki ME, Sharaf AM. "Power quality improvement using FACTS power filter compensation scheme" J Electr Syst 2013, 9(1), pp.86-96.

[11] Mahela OP, Shaik AG, Gupta N. "A critical review of detection and classification of power quality events" Renew Sustain Energy Rev 2015, 41, pp.495-505.

[12] Velamuri S, Sreejith S. "Power flow analysis incorporating renewable energy sources and FACTS devices" Int J Renew Energy Res 2017, 7(1), pp. $452-458$

[13] Crow ML. "Power quality enhancement using custom power devices" IEEE Power Energy Mag 2004, pp.2-50.

[14] Hingorani N. G. "Flexible AC Transmission" IEEE reprinted from IEEE Spectrum, Vol. 30, No.4, 1993, pp. 40-45.

[15] Cheng, H. In, I. and Chen S. "DC-Link Voltage Control and Performance Analysis of STATCOM", 2002.

[16] Yang, Z. Shen, C. Zhang, L. Crow M. L.” Integration of a STATCOM and Battery Energy Storage", IEEE Trans. on Power System, Vol. 16, no. 2, May 2001, pp. 254-260.

[17] Çöteli, "STATCOM ile Güç Akıș Kontrolü", Yüksek Lisans Tezi Elektrik Eğitimi, Fırat Üniversitesi Fen Bilimleri Enstitüsü Elazı̆̆, 2006.

[18] Jaime Cepeda, Esteban Agüero, "FACTS models for stability studies in DIgSILENT Power Factory" IEEE Transmission and Distribution Latin America, 2014; DOI: 10.1109/TDC-LA.2014.6955182.

[19] T. Sriyawong, P. Sriyanyong, P. Koseeyaporn and P. Kongsakorn "A Modified Fast Decoupled Power Flow Algorithm" International Energy Journal: Vol. 6, No.1, Part 2, June 2005, pp. 2-95.

[20] H. Feza Carlak, E Kayar, "TCR-TSC SVC Sistemler Kullanılarak Enerji İletim Sistemlerinde Gerilim Regülasyonu Analizi", 4th International Mediterranean Science and Engineering Congress IMSEC Alanya, 2019, pp. 476-481.

[21] Hingorani, Ng. Gyugy1, L. "Understanding FACTS: concepts and technology of flexible AC transmission systems" IEEE Press, New York, 2000.

[22] U. Arifoğlu, "Güç Sistemlerinin Bilgisayar Destekli Analizi”, Alfa Yayınları, İstanbul, 2002.

[23] C.A. Canizares, T.F. Zeno, "Analysis of SVC and TCSC Controllers in Voltage Collapse", IEEE Transactions on Power Systems, Vol. 14, No. 1, February 1999.

[24] R. Kowalak, "Resonant Conditions in a Node with an SVC Compensator," Acta Energetica, vol. 3, no.28, July 2016, pp. 70-75.

[25] Schauder, C. and Mehta, H. "Vector Analysis and Control of Advanced Static VAR Compensators", IEE Proceedings-C, Vol. 140, No.4, 1993, pp.299-306.

[26] S.M.Abd-Elazim, E.S.Ali, "Imperialist competitive algorithm for optimal STATCOM design in a multimachine power" International Journal of Electrical Power \& Energy Systems Vol. 76, March 2016, pp. 136-146.

[27] Md. Nazrul Islam, Md. Arifur Kabil, and Yashiro Kazushige "Design and Simulation of STATCOM to Improve Power Quality" International
Journal of Innovation and Applied Studies ISSN 2028-9324 Vol. 3, No.3, July 2013, pp. 871-878.

[28] Gyugyi, L. "Power Electronics in Electric Utilities: Static Var Compensators", Proceedings of The IEEE, vol. 76, no. 4, 1988, pp. 483493.

[29] Y. H. Song et al., Flexible AC Transmission Systems (FACTS), London: IEEE, 1999.

[30] Paserba J. "How FACTS Controllers Benefit AC Transmission System" Trans. And Dist. Con. and Exp., IEEE PES Volume 3, 7-12 Sept. vol.3 2003, pp. $949-956$.

[31] Acha E., Fuerte-Esquivel C., Ambriz-Pe'rez R., Angeles-Camacho H.,C., "FACTS Modelling and Simulation in Power Networks", John Wiley \& Sons LTD, 2004.

[32] Habur, K. D. O'Leary, 'FACTS-Flexible Alternating Current Transmission Systems-For Cost Effective and Reliable Transmission of Electrical Energy", 2000.

[33] Celal Yaşar, Yılmaz Aslan, Tarık Biçer, "Bir Dağıtım Tranformatörü Bölgesindeki Kayıpların İncelenmesi”, Dumlupınar Üniversitesi, Fen Bilimleri Enstitüsü Dergisi, Sayı 22, Ağustos 2010.

[34] J.P Navani, N.K Sharma, Sonal Sapra, "Technical and Non-Technical Losses in Power System and Its Economic Consequence in Indian Economy", International Journal of Electronics and Computer Science Engineering, ISSN: 2277-1956, 2012.

\section{BIOGRAPHIES}

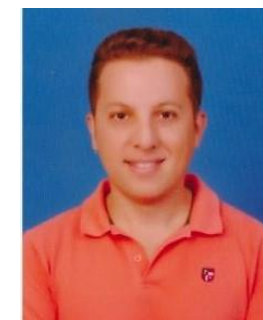

HAMZA FEZA CARLAK received the B.S. degree in electrical engineering from the Istanbul Technical University, Istanbul, in 2000 and the integrated Ph.D. degree in electrical and electronics engineering from Middle East Technical University, Ankara, in 2012.

From 2003 to 2013, he was a Research Assistant in the Middle East Technical University. Since 2017, he has been an Assistant Professor with the Electrical and Electronics Engineering Department, Akdeniz University. He is the author of more than 30 articles, and has an invention on the medical imaging modality. His research interests include power systems, medical imaging, thermal imaging, image processing, renewable energy and artificial neural network algorithms.

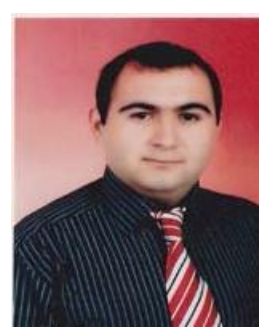

ERGIN KAYAR received the B.S. degree in electrical and electronics engineering from the Akdeniz University, Antalya, in 2017 and he has been doing a master's degree at Akdeniz University, Department of Electrical and Electronics Engineering. He has been working in Turkey Electrical Communication Corporation (TEIAS) as an electrical engineer for 8 years. His research interests include power systems, renewable energy and energy transmission systems. 


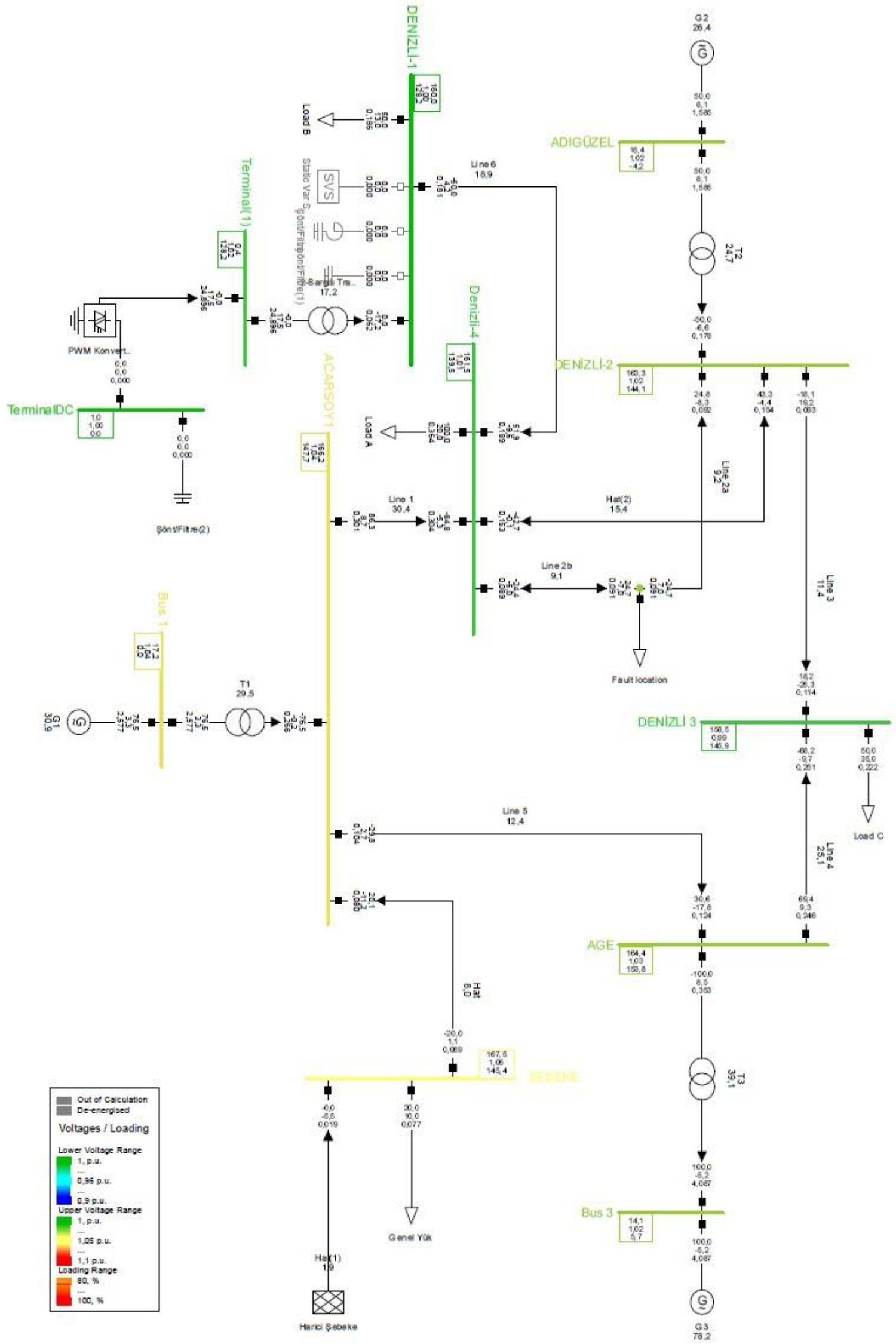

Fig.14. Western Mediterranean Energy Transmission System Network Model 